Review Article

\title{
Reviewing Interventions against Enterobacteriaceae in Broiler Processing: Using Old Techniques for Meeting the New Challenges of ESBL $E$. coli?
}

\author{
Michaela Projahn (D), Ewa Pacholewicz, Evelyne Becker, Guido Correia-Carreira, \\ Niels Bandick, and Annemarie Kaesbohrer
}

German Federal Institute for Risk Assessment, Diedersdorfer Weg 1, 12277 Berlin, Germany

Correspondence should be addressed to Michaela Projahn; michaela.projahn@bfr.bund.de

Received 2 August 2018; Revised 17 September 2018; Accepted 25 September 2018; Published 23 October 2018

Guest Editor: Maria E. Potes

Copyright ( 2018 Michaela Projahn et al. This is an open access article distributed under the Creative Commons Attribution License, which permits unrestricted use, distribution, and reproduction in any medium, provided the original work is properly cited.

\begin{abstract}
Extended-spectrum beta-lactamase- (ESBL-) producing Enterobacteriaceae are frequently detected in poultry and fresh chicken meat. Due to the high prevalence, an impact on human colonization and the spread of antibiotic resistance into the environment is assumed. ESBL-producing Enterobacteriaceae can be transmitted along the broiler production chain but also their persistence is reported because of insufficient cleaning and disinfection. Processing of broiler chickens leads to a reduction of microbiological counts on the carcasses. However, processing steps like scalding, defeathering, and evisceration are critical concerning fecal contamination and, therefore, cross-contamination with bacterial strains. Respective intervention measures along the slaughter processing line aim at reducing the microbiological load on broiler carcasses as well as preventing cross-contamination. Published data on the impact of possible intervention measures against ESBL-producing Enterobacteriaceae are missing and, therefore, we focused on processing measures concerning Enterobacteriaceae, in particular E. coli or coliform counts, during processing of broiler chickens to identify possible hints for effective strategies to reduce these resistant bacteria. In total, 73 publications were analyzed and data on the quantitative reductions were extracted. Most investigations concentrated on scalding, postdefeathering washes, and improvements in the chilling process and were already published in and before $2008(\mathrm{n}=42,58 \%)$. Therefore, certain measures may be already installed in slaughterhouse facilities today. The effect on eliminating ESBL-producing Enterobacteriaceae is questionable as there are still positive chicken meat samples found. A huge number of studies dealt with different applications of chlorine substances which are not approved in the European Union and the reduction level did not exceed 3 log10 values. None of the measures was able to totally eradicate Enterobacteriaceae from the broiler carcasses indicating the need to develop intervention measures to prevent contamination with ESBL-producing Enterobacteriaceae and, therefore, the exposure of humans and the further release of antibiotic resistances into the environment.
\end{abstract}

\section{Introduction}

Enterobacteriaceae that produce extended-spectrum betalactamases (ESBLs) are a challenging problem in human and veterinary medicine due to the limitations of the treatment options against infections caused by these resistant bacteria. In the beginning, ESBL-producing Enterobacteriaceae were only linked to human infections in hospitals. Nowadays, they are found to be widespread as intestinal gut colonizers in healthy humans as well as in animals and were also isolated from environmental samples like wastewater or fresh surface waters [1-3]. As also farm animals, especially broiler chickens, are affected by ESBL-producing E. coli (EEC), transmission via the food production chain from animals to humans is speculated $[4,5]$. Therefore, many studies were conducted to investigate the dissemination of these resistant bacteria in the broiler production. EEC were found in broiler breeder chickens and also in samples from broiler fattening farms even though there was no antibiotic treatment [6-11]. Moreover, in some studies broiler chickens were found to be already colonized with resistant bacteria in their first days of life 
[9]. Transmission investigations identified potential (pseudo)vertical transmission routes from (grand-)parent flocks to their offspring where the hatcheries played an important role in further spreading the resistant $E$. coli strains into the fattening flocks [12-15]. In addition, insufficient cleaning and disinfection procedures support the circulation of EEC on the farms and between subsequently fattened flocks $[16,17]$.

Further investigations focused on the occurrence of EEC in chicken retail meat and chicken food products. Proportions of up to $90 \%$ of EEC-positive samples were reported in some European studies [18-20]. Therefore, chicken meat is considered as a potential source of the transmission to humans. Insufficient kitchen hygiene in private households or hospitals might contribute to cross-contamination or transmission to humans $[21,22]$ even though the amount of detectable EEC on chicken filet or neck skin samples seemed to be low (range of 1 to $3.18 \log 10 \mathrm{CFU} / \mathrm{g}$ ) [23, 24].

Processing of broiler carcasses in slaughterhouses is very likely a critical point in the contamination of raw chicken meat. On one hand, EEC frequently occur as intestinal colonizers in broiler chickens and, therefore, fecal contamination during evisceration of carcasses might be possible [25, 26]. On the other hand, broiler chickens are obviously visibly contaminated on the skin and feathers with a mixture of feces and litter before entering the slaughterhouse [27, 28]. Unfortunately, there are only limited data on the occurrence of EEC during the processing of broiler chickens in the slaughterhouse. In the study of Pacholewicz et al., they found an overall reduction of EEC on broiler carcasses during processing [29]. However, in some of the investigated batches more than $2 \log$ EEC per carcass could be still detected after chilling. Therefore, intervention measures against these resistant bacteria in slaughterhouse facilities are needed to further reduce or even eliminate EEC from broiler processing plants and, therefore, also from chicken retail meat.

A lot of research was conducted to investigate intervention measures against Salmonella sp. or Campylobacter sp. in slaughterhouses [30] but to the best of our knowledge none of the studies examined the respective interventions concerning the usefulness to eradicate EEC. However, some studies concerning Salmonella sp. or Campylobacter sp. also determined the counts of E. coli, coliforms, or total Enterobacteriaceae in their samples. These data might give an indication of the effectiveness of a respective intervention against EEC in the processing plants as Enterobacteriaceae, in particular E. coli or coliforms, might function as indicator bacteria for EEC in the broiler processing line [31, 32].

In this review, we therefore provide an overview on data concerning intervention measures to quantitatively reduce E. coli, coliforms, or Enterobacteriaceae during processing of broiler chickens. We evaluated data from 73 original research papers and summarized the quantitative effects of the investigated interventions to reduce these bacteria at the different stages of the slaughter processing line (supplementary table (available here)). The studies comprise interventions to reduce/prevent the contamination of carcasses during processing as well as to remove the contamination that already occurred. There are also some data available concerning certain measures directly prior to the transport
TABLE 1: Overview of treatments/intervention measures prior to processing.

\begin{tabular}{|c|c|}
\hline Measures prior to processing & \\
\hline Age of broilers before slaughter & $42 \mathrm{~d}, 49 \mathrm{~d}, 56 \mathrm{~d}$ \\
\hline Feed withdrawal & $4 \mathrm{~h}$ to $16 \mathrm{~h}$ \\
\hline \multicolumn{2}{|l|}{ Replacement finisher } \\
\hline Feed additives & Glucose \\
\hline Water additives & $\begin{array}{c}\text { Chlorine, } \mathrm{MgSO}_{4} \text {, allostatic } \\
\text { modulator }\end{array}$ \\
\hline
\end{tabular}

of broiler chickens to the slaughterhouse to prevent fecal material from the fattening farms entering into the processing line as well as those measures which refer to slaughterhouse equipment or cleaning and disinfection procedures.

\section{Intervention Measures}

2.1. Prior to Processing. Despite general biosafety and biosecurity measures as well as cleaning and disinfection strategies in the fattening period of broiler chickens, further preprocessing factors like chicken age, feed withdrawal, or water and feed additives might lead to a reduced introduction of Enterobacteriaceae, in particular E. coli and coliforms, into the slaughterhouses and therefore reduced cross-contamination during carcass processing (Table 1 ).

It was found that increased age (56 days vs. 42 days) of broiler chicken led to higher contamination of the broiler carcasses with $E$. coli strains or coliforms after chilling in chlorinated water [33]. However, detailed data earlier in the processing line were not available and, therefore, data might be biased. Further studies investigated the influence of duration of feed withdrawal. In general, feed withdrawal of 8 to 10 hours is used to reduce the fecal amount in the gastrointestinal tract of broiler chickens and therefore a reduced probability of fecal contamination during automated evisceration is assumed $[34,35]$. However, in four different studies from three different countries, various outcomes were observed [33,36-38]. Results showed both a reduction and an increment of the E. coli amount on the carcasses in the different samplings suggesting insufficient effectiveness of the feed withdrawal concerning the reduction of E. coli. Furthermore, the effect of the feed withdrawal time varied between samples at different stations in the slaughter processing line [37]. This led to the assumption that the processing or certain steps of processing, e.g., evisceration, have a higher impact on the contamination rate of broiler carcasses with $E$. coli than the duration time of the feed withdrawal. In addition to feed withdrawal times, certain feed and water additives were investigated to enhance a possible positive effect of the feed withdrawal concerning the reduction of particular pathogens (Table 1). Substances like specialized replacement finisher [37], the supplementation of feed with a glucose cocktail [39], chlorine additives [36], or magnesium sulfate [40] in drinking water, or the supplementation of tap water with an allostatic modulator [38] were investigated. These substances were applied to broiler chickens prior to feed withdrawal. 
Again, various outcomes concerning a reduction of E. coli, Enterobacteriaceae, or coliforms concentrations on broiler carcasses were observed. Glucose feed additives and chlorine compounds in drinking water showed reductions of Enterobacteriaceae or E. coli in chicken crops [36, 39]. However, an impact on the reduction of $E$. coli on the broiler carcasses during processing and concerning the prevention on crosscontamination seemed to be ambiguous and needs further investigations. The supplementation of drinking water with magnesium sulfate at different levels led to a reduction of up to $2 \log 10$ values of the microbial cecum contents and coliform bacteria [40]. However, in these experiments neither the effect on E. coli counts nor EEC counts were investigated and therefore the application of magnesium sulfate needs to be further evaluated. Overall, the investigated measures do not provide a distinct strategy for the reduction of the introduction of E. coli into slaughterhouse facilities. However, positive effects of these measures on the reduction of EEC numbers on broiler carcasses were not yet published.

2.2. During Processing. The processing of broiler chickens consists of the following major steps: arrival at the slaughterhouse, stunning, bleeding, scalding, defeathering, evisceration, washing, chilling, and cutting/packaging. The summarized study data include intervention measures during general online slaughter procedures as well as experimental trials in pilot processing plants or under laboratory conditions for all processing steps except stunning and bleeding (Table 2). For both these steps, no data or studies could be identified.

2.2.1. After Arrival. Visible contamination of broiler chickens (on feathers and skin) is of great importance concerning the introduction of the bacteria into the slaughter facilities [27, 28]; however, there are only few studies which investigated measures before the scalding of the broiler chickens (Table 2).

In two independent studies, experimental prescald equipment was developed to brush broiler chickens before scalding to reduce the visible contamination and to lower the amount of fecal material and bacteria which were further introduced into the scalding water $[41,42]$. The entering of fecal material into the scalding water has an effect on the $\mathrm{pH}$ of the scalding water. It decreases due to dissociation of the ammonium urate, present in chicken feces, into uric acid and ammonium hydroxide [43] and thus influences heat resistance of Campylobacter and Salmonella [44, 45]. However, for E. coli the $\mathrm{pH}$ of the scalding water seems to be less important [46]. Both prescald brushing studies used slightly different techniques (whole surface vs. breast, vent, and neck areas) and reductions of up to $0.3 \log 10 \mathrm{CFU}$ of $E$. coli, coliforms, and Enterobacteriaceae on carcasses, respectively, might be achievable. The partial brushing of the breast, vent, and neck was not tested as an online treatment and, therefore, the effect after scalding could not be examined [42].

A second important contamination source is internal fecal material, which could contaminate carcasses due to leakage from the cloacae or gastrointestinal disruptions. Therefore, Northcutt et al. investigated in their study the impact of a forced cloacal fecal expulsion prior to scalding to prevent these leakages during further carcass processing [47]. They found no differences in the bacterial load between prescald washed, prescald squeezed, and prescald washed and squeezed carcasses but a comparison to untreated carcasses was not done. Musgrove et al. investigated the contribution of a cloacal plugging prior to electrocution of broilers to reduce numbers of Enterobacteriaceae on broiler carcasses [48]. The closure of the cloacae seemed to prevent further fecal contamination during processing as they determined reductions of $0.53 \log 10 \mathrm{CFU} / \mathrm{ml}$ per carcass rinse. In experimental inoculation trials, Buhr et al. also used manual cloacal plugging and vent suturing to prevent fecal leakage [49]. They found a reduction of $1.2 \log 10 \mathrm{CFU} / \mathrm{ml}$ breast skin rinse E. coli compared to broiler carcasses with open vents. Nevertheless, cloacal plugging is labor-consuming and is not yet established as an online procedure. However, it points to the fact that fecal leakage is a major problem in contamination of broiler carcasses.

Even though there are only limited studies on preprocessing measures, there might be a great potential in new strategies for the quantitative reduction of the bacterial load on broiler chickens before their processing.

2.2.2. Scalding. Scalding of carcasses is used to preliminary loose the feathers of broiler carcasses prior to the actual defeathering process. Two different systems of carcass scalding are established: immersion scalding in water bathes and stream/spray scalding. During immersion scalding, bacteria are removed by the effect of high temperature and a washing effect of the water bath. However, cross-contamination was shown during immersion scalding [50,51]. During steam scalding, bacteria are only reduced via a temperature effect but cross-contamination is expected to be less likely [52]. In the course of the development of the slaughter processing, different immersion scalding conditions have been established. Hard scalding with water temperatures from 60 to $66^{\circ} \mathrm{C}$ and immersion time of 45 to $90 \mathrm{~s}$ were typically used in the US poultry industry whereas in Europe soft scalding at 51 to $54^{\circ} \mathrm{C}$ with immersion times for 120 to $210 \mathrm{~s}$ is preferred [53]. The scalding conditions are also linked to the preferences of consumers with regard to certain attributes of fresh chicken meat like color of meat and skin [54] and the form of offer, chilled or frozen. Early data from artificial contamination trials of chicken skin with an E. coli K12 strain indicate that scalding temperatures above $60^{\circ} \mathrm{C}$ (scalding time of $150 \mathrm{~s}$ ) led to an increased reduction of this strain from the contaminated chicken skin [55]. They also concluded from their results that it seems to be difficult to totally remove the E. coli strain from the chicken skin as it is protected by polymers on the surface of the chicken skin. Mulder et al. found in their artificial contamination study that cross-contamination during scalding is very likely and that external contamination might be of greater importance than internal contamination [56]. Due to the need for enhanced hygiene measures to reduce microbiological contamination and consequently foodborne illnesses via poultry food products, further investigations were carried out to improve the 


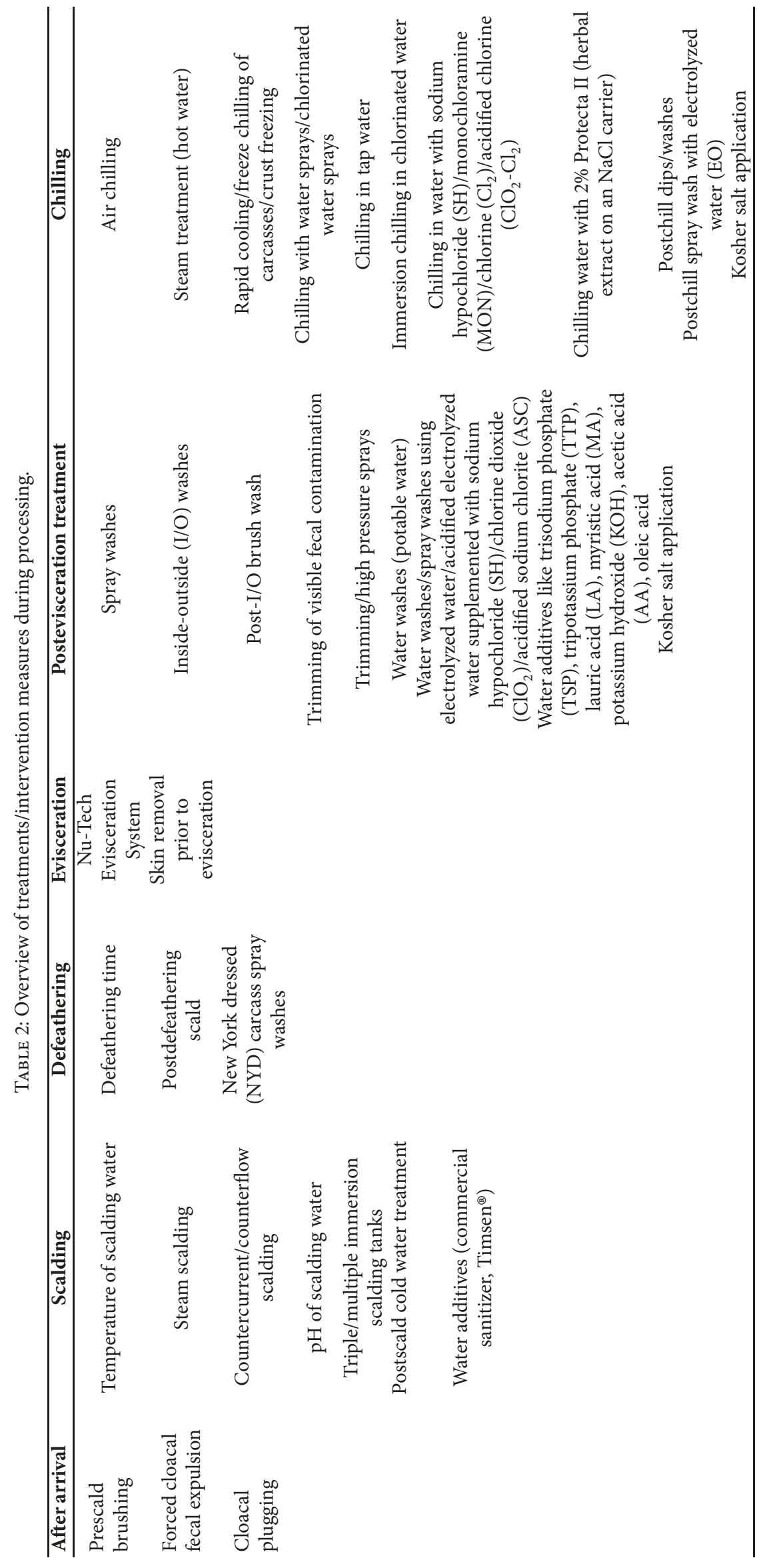


effectiveness of the scalding process without leading to a reduced meat quality and meat appearance.

Later on, countercurrent immersion scalding and additional postscald hot water sprays have been introduced [57]. However, the use of a three-tank counterflow scalder does not lead to a microbiological improvement of the contamination level of broiler carcasses compared to a single-tank scalder [58] although there was a reduction of aerobic bacteria in the last scalding tank. Berrang et al. found that the scalding in a counterflow triple-tank scalder decreased the E. coli counts from $4.6 \log 10 \mathrm{CFU}$ to $2.0 \log 10 \mathrm{CFU}$, but controls to other scalding techniques were not provided [59]. Further studies showed that variations in the $\mathrm{pH}$ of the scalding water [46] as well as technical developments of immersion scalders like triple-tank scalders [60], counterflow triple tanks [61], or an additional cold water scald [62] also had no distinct effect on the amount of $E$. coli or coliforms detected on the broiler carcasses. In contrast, the addition of copper sulfatebased sanitizers [63] or ammonium chloride substances [64] to the scalding water seemed to be of great advantage in reducing the amount of $E$. coli or coliforms on broiler carcasses. However, these substances are not approved for use in European slaughterhouses as there are no chemicals approved for use in the European Union (EU) [65]. Further variations in the scalding temperatures for immersion and spray scalders were not tested concerning their influence on the microbiological status of the carcasses. It also seems to be challenging to achieve an equal distributed scalding temperature at the different sites of the carcasses and to avoid a "cooked" skin appearance when using higher scalding temperatures [52].

Further scalding techniques like spray or vapor scalding have been tested as it was assumed that these methods would reduce water consumption and the amount of waste water [66] and might also reduce possible cross-contamination [52]. A prototype of a steam-hot-water-spray scalder was tested and showed a reduction of coliforms of approximately $0.5 \log 10 \mathrm{CFU} / \mathrm{cm}^{2}$ on carcass surface compared to a conventional scalder [67]. However, there were apparently no further data determined on the efficiency of these techniques to reduce the microbiological load on broiler carcasses.

As the scalding process of broiler carcasses was identified as a critical point for cross-contamination events with pathogenic foodborne bacteria $[50,51]$ as well as ESBLproducing Enterobacteriaceae $[24,68]$, it is necessary to improve the processing in the context of microbiological hygiene measures.

2.2.3. Defeathering. The defeathering process aims at the complete removal of the feathers from the broiler carcasses while keeping the skin and carcass appearance according to consumer preference. The defeathering machine consists of banks with sets of motor driven discs with rubber plucking fingers. This process also turned out to be critical concerning microbiological contamination of broiler carcasses as during defeathering the pressure may be released to the carcasses which frequently leads to fecal leakage [51, 6971]. It was recently shown that also cross-contamination with ESBL-producing Enterobacteriaceae can occur [24, 68].
Only few studies were conducted to investigate the impact of the defeathering process on microbiological contamination. Cason et al. found no significant difference in the numbers of $E$. coli of carcasses after mechanical defeathering for 30 $\mathrm{s}$ and $60 \mathrm{~s}$, respectively, in a laboratory processing facility [72]. Allen et al. reported that the majority of feathers with attached bacteria were already removed in the first $10 \mathrm{sec}$ of the defeathering process [70]. To possibly reduce the microbiological load on the carcasses directly after defeathering, hot water immersion scald and spray washer were investigated $[41,73,74]$. The studies found reductions between $0.2 \log 10$ and $0.7 \log 10$ of the $E$. coli load in the whole carcass rinses. However, limitations were alterations in meat quality and meat appearance due to high water temperatures and the use of chlorinated water which is not approved in the EU [65]. The effects of an application of acetic acid and hydrogen peroxide during defeathering on the microbiological quality were only tested for total aerobic plate counts but not for $E$. coli $[75]$.

Overall, there are only few studies available/published, which dealt with microbiological investigations during defeathering of carcasses. Respective studies might not be conducted or the investigations are just not available to the public. It also seems that further development of defeathering technology has a greater focus on processing parameters like defeathering efficacy than on microbiological aspects.

2.2.4. Evisceration. The aim of this processing step is to remove the total intestinal package. The whole evisceration process is highly automated and most challenging is the proper evisceration of highly variable sizes of broiler carcasses without leading to fecal leakage and gastrointestinal disruptions. There is limited information about the effectiveness and possible microbiological contamination due to the technologies used for every single evisceration step. Russel et al. did early comparisons between the $\mathrm{Nu}$-Tech Evisceration System and a conventional Streamlined Inspection System (SIS). Evisceration with the $\mathrm{Nu}$-Tech system leads to the separation of the visceral package from the carcass for inspection whereas with the SIS the package remains attached to the carcass. The Nu-Tech system showed better performance concerning the visible fecal contamination of the carcasses but no difference in the amount of $E$. coli in the investigated carcass rinses between both systems was observed [76].

Compliance with procedures to set and control equipment may be also associated with presence of fecal contamination [77]. This contamination occurs as a result of damage of the intestines due to heterogeneity of carcasses within and between flocks. Conventional equipment cannot be adjusted per carcass; however, evisceration employees can adjust it for a particular flock to minimize the fecal leakage. The observed association between compliance with procedures and occurrence of fecal contamination needs to be validated in intervention studies.

The structure of the skin of broiler chickens is assumed to play an important role in level of observable microbiological contamination due to the properties of the skin surface and the associated polymers which can protect bacteria from removal $[55,78]$. Therefore, whether the removal of the skin 
prior to evisceration can lead to reduced contamination of the chicken meat was investigated. After manual evisceration, they found a reduction of $0.5 \log 10 \mathrm{CFU} /$ carcass of $E$. coli and coliforms, respectively [79]. However, the possible reduction of contamination with Enterobacteriaceae by removing broiler chicken skin before evisceration was not tested as an online operation.

2.2.5. Postevisceration Treatment. Leakage of fecal material and contamination with bacteria occur due to improper efficiency of the evisceration. Therefore, a high number of investigations were conducted to improve the removal of (visible) fecal contamination on broiler carcasses by improving the washing technologies as well as adding various substances to the washing water.

Early examinations on spray washing and inside-outside (I/O) washers revealed slight reductions of Enterobacteriaceae on broiler carcasses due to this application [80]. Further investigations of I/O washers also found only slight reductions of the $E$. coli and coliform count, respectively, even though chlorinated water was used for the washing process which is not approved in the $\mathrm{EU}[41,65,74,80,81]$. Furthermore, it was shown that an I/O wash with a showering time of $5 \mathrm{~s}$ to $6 \mathrm{~s}$ does not completely remove visible fecal contamination and, therefore, is less effective in reducing E. coli, Enterobacteriaceae, or coliforms from contaminated broiler carcasses [25]. Berrang and Baily examined a post-I/O brush wash step and found an additional reduction of about $0.5 \log 10$ CFU of E. coli and coliforms, respectively [41]. The trimming of visible fecal contamination with different water pressure resulted in a lower reduction of these bacteria [82] and the usage of high pressure spray with chlorinated water showed varying outcomes in the ability to reduce Enterobacteriaceae from broiler carcasses [83]. Studies also investigated the efficiency of water washes to reduce the numbers of E. coli or coliforms on broiler carcasses. Experiments were carried out in the lab or in experimental pilot processing plants and it turned out that using water with less than 2 ppm chlorine or potable water for the washing steps led to reductions between 0.3 and $1.3 \log 10 \mathrm{CFU}$ of E. coli, coliforms, or Enterobacteriaceae [82, 84, 85].

Most of the interventions against E. coli, coliforms, or Enterobacteriaceae on broiler carcasses by different washing steps or technologies after the evisceration include the usage of chlorinated water (produced, e.g., by adding sodium hypochloride $(\mathrm{SH})$, or by electrolyzing water containing dissolved sodium chloride) which is not approved in the EU [65]. Here, investigations in the lab or in processing plants showed better results concerning the reduction of E. coli, coliforms, and Enterobacteriaceae, respectively, than online investigations in the slaughterhouse [84-87]. Furthermore, a study concerning online postevisceration washes with chlorinated water resulted in higher bacterial contamination than without chlorinated water [74]. The same was found in a study concerning prechill washes [41] whereas chlorine dioxide $\left(\mathrm{ClO}_{2}\right)$ spray wash seems to reduce $E$. coli and coliform counts about $0.4 \log 10 \mathrm{CFU}$, respectively [74]. Kemp et al. investigated the possible usage of acidified sodium chlorite (ASC) as an intervention against $E$. coli contamination on broiler carcasses $[88,89]$. They conducted lab work experiments and combined online treatments and found reductions between 0.77 and $2.28 \log 10$ CFU.

Further substances like trisodium phosphate (TSP), lauric acid (LA), myristic acid (MA), or potassium hydroxide $(\mathrm{KOH})$ were also tested in further studies as candidates to potentially reduce E. coli, coliforms, or Enterobacteriaceae counts on broiler carcasses after the evisceration step. Outcomes vary between 0.33 and $2.07 \log 10 \mathrm{CFU}$ reduction [74, 85, 90, 91]. Acetic acid (1.4 g/l and $2.8 \mathrm{~g} / 1 \mathrm{AA})$ and oleic acid as a $10 \%$ washing solution were also tested in lab experiments. They showed reductions of up to $0.93 \log 10$ CFU of E. coli and $2.43 \log 10 \mathrm{CFU}$ of Enterobacteriaceae, respectively, on poultry skin samples [92, 93]. For kosher chicken meat production, the usage of salt was evaluated after the evisceration step of the carcasses [94]. During their investigation, they found that kosher salt application can reduce the E. coli and coliform counts by 2.81 and $2.31 \log 10$ CFU, respectively.

Most of the studies dealt with washing substances which are not approved in Europe [65] (Table 2). It turned out that the addition of chlorine compounds does not lead to a total removal of Enterobacteriaceae on broiler carcasses and also more natural substances might have a potential to reduce these bacteria on broiler carcasses during processing. However, most investigations were done as lab work or in pilot processing plants and the results need to be further evaluated.

2.2.6. Chilling. The chilling process in general can lead to a reduction of the $E$. coli amount on broiler carcasses of up to $3.5 \log 10$ values $[95,96]$. However, broiler carcasses are still contaminated with E. coli, coliforms, or Enterobacteriaceae after chilling. This was also to be found for multidrug resistant E. coli like EEC [97-99].

Chilling of broiler carcasses is done via immersion chilling in a water tank, chilling in air, or air-spray chilling where carcasses are sprayed with water at several points in the chilling room. Furthermore, some slaughterhouses use a combination of immersion and air chilling having a water bath with cold water only in the beginning of the chilling room. The chilling method applied depends on the scalding temperature regime. If the scalding temperatures are very high, the epidermis is removed and the carcasses need to be kept wet through the process; otherwise, the appearance of the chicken skin/meat is affected. Therefore, chilling in a water bath is applied in combination with high temperature scalding.

The use of a water bath during chilling-like the scalding water bath-might also contribute to cross-contamination between carcasses but experimental studies on air chilling with or without chlorinated water sprays did not result in reductions of the amount of $E$. coli or coliforms on the broiler carcasses [100-105]. The use of steam or hot water in combination with rapid cooling, chilling, or freezing seems to reduce up to $2.83 \log 10 \mathrm{CFU}$ of $E$. coli depending on the treatment time [106]. However, there are disadvantages 
in the skin appearance and skin color [106]. Freeze chilling of chicken meat for longer transportation was investigated with no negative effect on the meat appearance and found to possibly reduce up to $1 \log 10 \mathrm{CFU}$ of Enterobacteriaceae on the chicken meat [107]. In contrast, an experimental trial on the survival of E. coli K12 during crust freezing resulted only in reductions $0.3 \log 10 \mathrm{CFU}$ [108]. Allen et al. investigated (chlorinated) water sprays for carcass chilling but the effect in reducing coliforms from breast skin was not more than 0.62 $\log 10$ CFU even when using $250 \mathrm{ppm}$ of chlorine [100].

Immersion chilling in tap water showed reductions of up to $1.1 \log 10 \mathrm{CFU}$ of $E$. coli under laboratory conditions compared to unchilled carcasses [109]. Chilling in water with less than $2 \mathrm{ppm}$ free chlorine residues reduced $E$. coli counts by $1.34 \log 10$ CFU [110]. In the same study, after renewal of the chilling water after $8 \mathrm{~h}$ (instead of $16 \mathrm{~h}$ ) the reduction was determined as $1.25 \log 10 \mathrm{CFU}$ of E. coli. In most of the studies, the use of chlorine substances or solutions like acidified chlorine, sodium hypochlorite $(\mathrm{SH})$, monochloramine $(\mathrm{MON})$, or chlorine dioxide $\left(\mathrm{ClO}_{2}\right)$ for the reduction of bacterial contamination on broiler carcasses was investigated $[25,33,60,74,111-113]$. On the one hand, reductions of up to $1.4 \log 10 \mathrm{CFU}$ of $E$. coli were detected. On the other hand, also increments of the amount of $E$. coli (up to $0.2 \log 10 \mathrm{CFU}$ ) were found. This might be due to the sampling of different slaughterhouses and different sampling conditions/methods and laboratory work. In the study by Kameyada et al., they found that also the chilling temperature might have an influence on the reduction of $E$. coli counts on broiler carcasses [112]. To further reduce the bacterial contamination from the carcasses and additionally prevent cross-contamination, Dickens et al. investigated an herbal extract as additive in the chilling water [109]. In their laboratory, they determined reductions of $2 \log 10 \mathrm{CFU}$ and $2.64 \log 10 \mathrm{CFU}$ for E. coli and coliforms, respectively. Postchill washing or dipping steps in chlorinated water can lead to additional reductions between 0.2 and $1.74 \log 10 \mathrm{CFU}$ of $E$. coli or coliforms on the broiler carcasses [74, 81, 87]. A prechill or postchill application of kosher salt to the carcasses was found to reduce E. coli counts by $1.39 \log 10$ CFU and 1.77 log10 CFU, respectively [94].

The analysis of various published papers concerning the microbiologic profile of broiler carcasses after chilling highlights the need for harmonized methods and sampling procedures. It also shows that, in concordance to the postevisceration wash, the adding of chlorine compounds to the chilling water does not completely remove Enterobacteriaceae from the broiler carcasses assuming that methods for preventing contamination of broiler carcasses might be of greater importance.

2.3. Packaging. There are different technologies established to protect raw meat from recontamination and to prevent the growth of potential pathogenic bacteria [114]. For the preservation of chicken meat, investigations were conducted to improve the shelf life and to reduce bacterial contamination (Table 3). Various combinations of gaseous substances and concentrations were tested in modified atmosphere packaging (MAP) processes. Most common are combinations
TABLE 3: Overview of packaging treatments/intervention.

\begin{tabular}{lc}
\hline Packaging & Substances \\
\hline $\begin{array}{l}\text { Modified atmosphere } \\
\text { packaging (MAP) }\end{array}$ & Various combinations of $\mathrm{O}_{2}, \mathrm{CO}_{2}$, and \\
Decontamination & $\mathrm{N}_{2}$ \\
Active packaging & Water extract of sumac, lauric acid \\
& $(\mathrm{LA})$, high-intensity pulsed light \\
& Carvacrol, cinnamaldehyde, \\
ovotransferrin, potassium sorbate
\end{tabular}

of the gases $\mathrm{O}_{2}, \mathrm{CO}_{2}$, and $\mathrm{N}_{2}$. Depending on the storage time investigated in the studies, most of the tested MAP gases showed reduced growth of $E$. coli or Enterobacteriaceae compared to the storage under air conditions [107, 115-117]. High portions of $\mathrm{CO}_{2}$ in the gaseous mixtures seemed to better reduce the growth of $E$. coli on chicken meat $[116,117]$. However, none of the tested MAP processes led to a total reduction of $E$. coli counts on chicken meat. The shelf life of chicken meat is not only dependent on the amount of E. coli on the respective filets or chicken wings. Therefore, most of the investigations on MAP also concentrate on other bacteria like pseudomonads and other potential pathogenic Enterobacteriaceae as well as meat appearance and consumer preferences $[54,114,118]$. As alternatives to MAP, active packaging has been developed which leads to an interaction of the packaging material and the respective meat [119]. Furthermore, the packaging material can be incorporated with different (reactive) substances to increase the shelf life due to the interaction of material, substances, and meat. The substances allowed for use for active packaging are also strictly regulated in the EU [119]. The incorporation of 3\% carvacrol or 3\% cinnamaldehyde into wrapping films reduced the amount of E. coli O157:H7 on chicken breast samples of up to 6.8 and $5.2 \log 10 \mathrm{CFU}$, respectively, after storage time of $72 \mathrm{~h}$ at $23^{\circ} \mathrm{C}$ [120]. Using ovotransferrin or potassium sorbate showed reductions of more than $2 \log 10$ CFU of $E$. coli only in combination with $5 \mathrm{mM}$ EDTA whereas the reduction due to EDTA alone was higher than for both separate substances [121]. Besides the packaging technology, the decontamination of chicken meat with a water extract of sumac (WES) and 2\% lactic acid (LA) was investigated in a broiler wing model [122]. Reductions up to $2 \log 10 \mathrm{CFU}$ of coliforms were detected compared to a distilled water reference. Haughton et al. determined the decontamination of chicken meat using highintensity pulsed light (HIPL) and found a reduction of up to $1.51 \log 10 \mathrm{CFU}$ of E. coli on uncovered chicken skin [123]. However, the use of HIPL on packaged chicken meat/skin led to a lower reduction of the E. coli amount.

None of the investigated interventions was tested for their efficacy against EEC. However, it seems that the reduction or eradication of EEC needs to be done in previous steps in the processing of broiler chickens.

2.4. Equipment/Others. Despite direct intervention measures to reduce E. coli, coliforms, or Enterobacteriaceae on broiler carcasses also few investigations on the reduction of bacterial contaminants in the slaughterhouse environment were conducted (Table 4). These investigations include the general 
TABLE 4: Overview of treatments of equipment/slaughterhouse environment.

\begin{tabular}{l}
\hline Equipment \\
\hline Conveyor treatment \\
Disinfectants (peracetic acid and quaternary ammonium, sodium \\
hypochloride (SH), peracetic acid) \\
Transport crate treatment \\
LEDs/UV light \\
\hline
\end{tabular}

sanitary treatment in slaughterhouses and the disinfection of conveyor belts and transport crates. In the study of Kašková et al., no coliforms were detected on the sampled sites, except for the shackling hooks, after disinfection with quaternary ammonium compounds [124]. For the sanitizing of stainless steel sodium hypochloride $(\mathrm{SH})$ and peracetic acid were tested under laboratory conditions [125]. From the results, the authors did not recommend peracetic acid as a sanitizing agent for slaughterhouse equipment. Cleaning and disinfection of conveyor belts and transport crates are critical concerning cross-contamination. Hot water treatment does not result in significant reduction of Enterobacteriaceae whereas washing, soaking, and the additional use of disinfectants or detergents are more effective [126-128]. Ultrasonic treatment of conveyor belts was more effective in combination with water temperatures around $60^{\circ} \mathrm{C}$ [127]. These studies show that the disinfection of the slaughterhouse equipment or transport crates is a critical process and needs to be done accurately to avoid cross-contamination and further spread of the bacteria.

For the decontamination of chilling wash water Rowan et al. tested a pulsed-plasma gas discharge system [129]. They found a reduction of approx. $8 \log 10$ CFU of E. coli NCTC9001 after a treatment time of $18 \mathrm{sec}$. UV irradiation and LED light were further methods tested for the decontamination of stainless steel and chicken skin $[130,131]$. UV irradiation showed better results concerning the reduction of E. coli on stainless steel (up to $5.34 \log 10 \mathrm{CFU}$ ) than on chicken skin (up to $1.28 \log 10 \mathrm{CFU}$ ) [130]. This is assumed to be due to the rough surface of the chicken skin and the feather follicles which protect bacteria from the UV light. The LED array treatment did not exceed $1 \log 10 \mathrm{CFU}$ reduction on stainless steel and chicken skin, respectively [131]. Furthermore, the treatment period ranged between 10 and 20 min which might be problematic for an installation as online treatment.

There is a high diversity in methods tested for the inactivation or reduction of Enterobacteriaceae or E. coli counts in slaughterhouses or slaughterhouse equipment. However, most of the methods were not tested for their potential to also reduce contamination on chicken carcasses or as an online intervention in a slaughterhouse.

\section{Summary and Conclusion}

ESBL-producing Enterobacteriaceae are frequently detected in broiler chickens and chicken meat. Due to high prevalence of these usually multidrug resistant bacteria, an impact on human health is assumed $[4,5]$. It was recently reported that reduced exposure to humans also led to a reduction in the prevalence in humans [132]. The transmission along the broiler production chain and certain cross-contamination events have been described by various authors [12-15]. Furthermore, it has been reported that wastewater from processing facilities contributes to the spread of multidrug resistant bacteria into the environment [133-136]. Therefore, interventions are needed to reduce or even eradicate these ESBL-producing Enterobacteriaceae from the broiler production.

Until now certain interventions were investigated against Campylobacter sp. and/or Salmonella sp. but specific interventions against EEC were not evaluated. We, therefore, summarized data from various studies which also investigated Enterobacteriaceae counts with E. coli and coliforms in particular as they might function as indicator bacteria for EEC in the broiler processing line $[31,32]$.

Overall, we found 73 studies providing data on the quantitative reduction of $E$. coli, coliforms, or Enterobacteriaceae along the different steps of the broiler processing line (supplementary table). Reductions were measured up to $3 \log 10$ CFU on chicken skin or broiler carcasses; however, none of the methods led to total eradication of those bacteria. A variety of investigated measures provided only reductions below $1 \log 10$ CFU or even caused an increase in the respective bacterial counts indicating an insufficient effect against E. coli, coliforms, or Enterobacteriaceae contamination of broiler carcasses and, therefore, an effect on EEC is questionable. In addition, it seems that experimental intervention trials provide better results than measures implemented as online treatment. Also, the effect of measures dependent on the contamination level of broiler carcasses is not well investigated. The application of simultaneous or parallel interventions might have an additive effect; however, respective studies for most of the interventions are missing.

We found studies comprising interventions to prevent fecal material from the fattening farms entering into the processing line of the slaughterhouse (measures prior to processing and after arrival), to reduce/prevent the contamination of carcasses during processing (scalding, evisceration) as well as to remove contamination that already occurred (postevisceration treatment, chilling, packaging, and equipment/others). It was already reported that the structure of the chicken skin plays an important role in attachment of bacteria and that firmly attached bacteria during plucking are more difficult to remove $[51,55,137]$. This might suggest that there is a need for more measures that prevent contamination from occurring.

Twenty-one measures dealt with the application of various chlorine substances which are not approved in the EU [65]. The overall reduction of E. coli, coliforms, or Enterobacteriaceae by these substances was less than $2.3 \log 10 \mathrm{CFU}$, indicating that chlorine does not remove E. coli, coliforms, or Enterobacteriaceae from broiler carcasses to a preferable amount. Again, taking into account the important issue of skin structure and the bacterial attachment, it could be concluded that there are general limitations to the effectiveness of decontaminating chicken carcasses. It could be of interest to develop more interventions preventing the introduction 
or the recontamination with Enterobacteriaceae especially under the current EU regulations where decontamination is not approved. From our collection, 42 studies were already published before 2008 and, therefore, it is very likely that some of these measures are already installed in slaughterhouses. Furthermore, $58 \%$ of the studies $(n=42)$ were conducted in the USA and only $21 \%$ in European countries $(n=15)$ which highlights the need for further investigations in the EU due to differences in the respective guidelines and European decrees.

In the study of Pacholewicz et al., they found an overall reduction of EEC on broiler carcasses during processing [29]. However, they also detected differences in the reduction during processing of E. coli and EEC populations in one slaughterhouse. Here, EEC were less reduced than the numbers of total $E$. coli after defeathering and after evisceration, respectively. Furthermore, the effect of a respective processing step on the reduction of EEC additionally illustrated differences between two slaughterhouses [29]. This indicates that also slaughterhouses specific intervention measures might be needed against the dissemination of EEC. In addition, effective measures might depend on the current equipment, procedures, and technologies used in every single slaughterhouse, which need to be further evaluated.

Nevertheless, there is a need to eliminate as much as possible at various stages of processing (through preventing fecal contamination from entering a particular step) and maintaining and/or further reducing the amount of bacteria achieved at a respective processing step. EEC do not only spread in the broiler production line but can also be spread into the environment via wastewater and, therefore, contribute to the transmission of antibiotic resistance factors. Intervention measures are needed to prevent the spread and cross-contamination of these resistant bacteria during slaughter and finally the transmission into the environment and the households via contaminated chicken meat.

\section{Conflicts of Interest}

The authors declare that they have no conflicts of interest.

\section{Acknowledgments}

This work was funded by the Federal Office for Agriculture and Food (BLE) EsRAM Consortium (grant no.: 2817701614).

\section{Supplementary Materials}

Supplementary table: published study data on quantitative reductions of $E$. coli, coliforms, or Enterobacteriaceae in the broiler processing line (negative reductions meaning an increase in the bacterial load are marked in red). (Supplementary Materials)

\section{References}

[1] H. Blaak, G. Lynch, R. Italiaander, R. A. Hamidjaja, F. M. Schets, and A. M. de Roda Husman, "Multidrug-resistant and extended spectrum beta-lactamase-producing Escherichia coli in Dutch surface water and wastewater," PLOS ONE, vol. 10, no. 6, Article ID e0127752, 2015.

[2] A. Kaesbohrer, A. Schroeter, B.-A. Tenhagen, K. Alt, B. Guerra, and B. Appel, "Emerging antimicrobial resistance in commensal escherichia coli with public health relevance," Zoonoses and Public Health, vol. 59, no. 2, pp. 158-165, 2012.

[3] A. F. C. Leonard, L. Zhang, A. J. Balfour et al., "Exposure to and colonisation by antibiotic-resistant E. coli in UK coastal water users: Environmental surveillance, exposure assessment, and epidemiological study (Beach Bum Survey)," Environment International, vol. 114, pp. 326-333, 2018.

[4] B. Lazarus, D. L. Paterson, J. L. Mollinger, and B. A. Rogers, "Do human extraintestinal escherichia coli infections resistant to expanded-spectrum cephalosporins originate from foodproducing animals? A systematic review," Clinical Infectious Diseases, vol. 60, no. 3, pp. 439-452, 2015.

[5] A. I. Vitas, D. Naik, L. Pérez-Etayo, and D. González, "Increased exposure to extended-spectrum $\beta$-lactamaseproducing multidrug-resistant Enterobacteriaceae through the consumption of chicken and sushi products," International Journal of Food Microbiology, vol. 269, pp. 80-86, 2018.

[6] V. Bortolaia, L. Guardabassi, M. Trevisani, M. Bisgaard, L. Venturi, and A. M. Bojesen, "High diversity of extendedspectrum $\beta$-lactamases in Escherichia coli isolates from Italian broiler flocks," Antimicrobial Agents and Chemotherapy, vol. 54, no. 4, pp. 1623-1626, 2010.

[7] D. Costa, L. Vinué, P. Poeta et al., "Prevalence of extendedspectrum beta-lactamase-producing Escherichia coli isolates in faecal samples of broilers," Veterinary Microbiology, vol. 138, no. 3-4, pp. 339-344, 2009.

[8] A. Dame-Korevaar, E. A. J. Fischer, A. Stegeman et al., "Dynamics of CMY-2 producing E. coli in a broiler parent flock," Veterinary Microbiology, vol. 203, pp. 211-214, 2017.

[9] C. M. Dierikx, J. A. Van Der Goot, H. E. Smith, A. Kant, and D. J. Mevius, "Presence of ESBL/AmpC -producing Escherichia coli in the broiler production pyramid: A descriptive study," PLoS ONE, vol. 8, no. 11, 2013.

[10] C. A. Ginns, G. F. Browning, M. L. Benham, G. A. Anderson, and K. G. Whithear, "Antimicrobial resistance and epidemiology of Escherichia coli in broiler breeder chickens," Avian Pathology, vol. 25, no. 3, pp. 591-605, 1996.

[11] S. S. Mo, M. Norström, J. S. Slettemeas, A. Lovland, A. M. Urdahl, and M. Sunde, "Emergence of AmpC-producing Escherichia coli in the broiler production chain in a country with a low antimicrobial usage profile," Veterinary Microbiology, vol. 171, no. 3-4, pp. 315-320, 2014.

[12] Y. Agerso, J. D. Jensen, H. Hasman, and K. Pedersen, "Spread of extended spectrum cephalosporinase-producing escherichia coli clones and plasmids from parent animals to broilers and to broiler meat in a production without use of cephalosporins," Foodborne Pathogens and Disease, vol. 11, no. 9, pp. 740-746, 2014.

[13] S. Börjesson, T. Guillard, A. Landén, B. Bengtsson, and O. Nilsson, "Introduction of quinolone resistant Escherichia coli to Swedish broiler population by imported breeding animals," Veterinary Microbiology, vol. 194, pp. 74-78, 2016.

[14] M. Projahn, K. Daehre, U. Roesler, and A. Friese, "ESBL/pAmpC-producing enterobacteria in the broiler hatchery - a mode of pseudo-vertical transmission?" Applied and Environmental Microbiology, vol. 83, 2017. 
[15] M. Projahn, K. Daehre, T. Semmler, S. Guenther, U. Roesler, and A. Friese, "Environmental adaptation and vertical dissemination of ESBL-/pAmpC-producing Escherichia coli in an integrated broiler production chain in the absence of an antibiotic treatment," Microbial Biotechnology, 2018.

[16] K. Daehre, M. Projahn, T. Semmler, U. Roesler, and A. Friese, "Extended-spectrum beta-lactamase-/AmpC beta-lactamaseproducing enterobacteriaceae in broiler farms: transmission dynamics at farm level," Microbial Drug Resistance, vol. 24, no. 4, pp. 511-518, 2018.

[17] K. Y. Luyckx, S. Van Weyenberg, J. Dewulf et al., "On-farm comparisons of different cleaning protocols in broiler houses," Poultry Science, vol. 94, no. 8, pp. 1986-1993, 2015.

[18] T. Casella, M. C. L. Nogueira, E. Saras, M. Haenni, and J.Y. Madec, "High prevalence of ESBLs in retail chicken meat despite reduced use of antimicrobials in chicken production, France," International Journal of Food Microbiology, vol. 257, pp. 271-275, 2017.

[19] P. Egea, L. López-Cerero, E. Torres et al., "Increased raw poultry meat colonization by extended spectrum beta-lactamaseproducing Escherichia coli in the south of Spain," International Journal of Food Microbiology, vol. 159, no. 2, pp. 69-73, 2012.

[20] L. P. Randall, M. P. Lodge, N. C. Elviss et al., "Evaluation of meat, fruit and vegetables from retail stores in five United Kingdom regions as sources of extended-spectrum beta-lactamase (ESBL)-producing and carbapenem-resistant Escherichia coli," International Journal of Food Microbiology, vol. 241, pp. 283290, 2017.

[21] A. J. Stewardson, G. Renzi, N. Maury et al., "Extended-spectrum $\beta$-lactamase-producing enterobacteriaceae in hospital food: A risk assessment," Infection Control and Hospital Epidemiology, vol. 35, no. 4, pp. 375-383, 2014.

[22] G. A. Younis, R. M. Elkenany, M. A. Fouda, and N. F. Mostafa, "Virulence and extended-spectrum $\beta$-lactamase encoding genes in Escherichia coli recovered from chicken meat intended for hospitalized human consumption," Veterinary World, vol. 10, no. 10, pp. 1281-1285, 2017.

[23] F. Reich, F. Schill, V. Atanassova, and G. Klein, "Quantification of ESBL-Escherichia coli on broiler carcasses after slaughtering in Germany," Food Microbiology, vol. 54, pp. 1-5, 2016.

[24] P. von Tippelskirch, G. Gölz, M. Projahn et al., "Prevalence and quantitative analysis of ESBL and AmpC beta-lactamase producing Enterobacteriaceae in broiler chicken during slaughter in Germany," International Journal of Food Microbiology, vol. 281, pp. 82-89, 2018.

[25] S. M. Jiménez, M. C. Tiburzi, M. S. Salsi, M. E. Pirovani, and M. A. Moguilevsky, "The role of visible faecal material as a vehicle for generic Escherichia coli, coliform, and other enterobacteria contaminating poultry carcasses during slaughtering," Journal of Applied Microbiology, vol. 95, no. 3, pp. 451-456, 2003.

[26] D. P. Smith, J. K. Northcutt, J. A. Cason, A. Hinton Jr., R. J. Buhr, and K. D. Ingram, "Effect of external or internal fecal contamination on numbers of bacteria on prechilled broiler carcasses," Poultry Science, vol. 86, no. 6, pp. 1241-1244, 2007.

[27] J. A. Cason, A. Hinton Jr., J. K. Northcutt et al., "Partitioning of external and internal bacteria carried by broiler chickens before processing," Journal of Food Protection, vol. 70, no. 9, pp. 20562062, 2007.

[28] K. L. Kotula and Y. Pandya, "Bacterial contamination of broiler chickens before scalding," Journal of Food Protection, vol. 58, no. 12, pp. 1326-1329, 1995.
[29] E. Pacholewicz, A. Liakopoulos, A. Swart et al., "Reduction of extended-spectrum- $\beta$-lactamase- and AmpC- $\beta$-lactamaseproducing Escherichia coli through processing in two broiler chicken slaughterhouses," International Journal of Food Microbiology, vol. 215, pp. 57-63, 2015.

[30] J. M. Cox and A. Pavic, "Advances in enteropathogen control in poultry production," Journal of Applied Microbiology, vol. 108, no. 3, pp. 745-755, 2010.

[31] B. G. Matias, P. S. D. A. Pinto, M. V. C. Cossi, and L. A. Nero, "Salmonella spp. and hygiene indicator microorganisms in chicken carcasses obtained at different processing stages in two slaughterhouses," Foodborne Pathogens and Disease, vol. 7, no. 3, pp. 313-318, 2010.

[32] P. K. Saini, H. M. Marks, M. S. Dreyfuss, P. Evans, L. Victor Cook Jr., and U. Dessai, "Indicator organisms in meat and poultry slaughter operations: Their potential use in process control and the role of emerging technologies," Journal of Food Protection, vol. 74, no. 8, pp. 1387-1394, 2011.

[33] J. K. Northcutt, M. E. Berrang, J. A. Dickens, D. L. Fletcher, and N. A. Cox, "Effect of broiler age, feed withdrawal, and transportation on levels of coliforms, Campylobacter, Escherichia coli and Salmonella on carcasses before and after immersion chilling," Poultry Science, vol. 82, no. 1, pp. 169-173, 2003.

[34] S. F. Bilgili, "Effect of feed and water withdrawal on shear strength of broiler gastrointestinal tract.", Poultry Science, vol. 67, no. 5, pp. 845-847, 1988.

[35] C. J. Wabeck, "Feed and water withdrawal time relationship to processing yield and potential fecal contamination of broilers," Poultry Science, vol. 51, no. 4, pp. 1119-1121, 1972.

[36] F. R. Barreiro, S. M. Baraldi-Artoni, F. R. Pinto, M. M. C. Barbosa, J. C. Barbosa, and L. A. Amaral, "Influence of chlorine added to drinking water during the preslaughter feed withdrawal on microbiology and morphology of the broiler gastrointestinal tract," Poultry Science, vol. 91, no. 11, pp. 27782784, 2012

[37] J. K. Northcutt, R. J. Buhr, M. E. Berrang, and D. L. Fletcher, "Effects of replacement finisher feed and length of feed withdrawal on broiler carcass yield and bacteria recovery," Poultry Science, vol. 82, no. 11, pp. 1820-1824, 2003.

[38] M. E. Rubio-García, M. S. Rubio-Lozano, E. Ponce-Alquicira, C. Rosario-Cortes, G. M. Nava, and M. P. Castañeda-Serrano, "Improving appearance and microbiologic quality of broiler carcasses with an allostatic modulator," Poultry Science, vol. 94, no. 8, pp. 1957-1963, 2015.

[39] A. Hinton Jr., R. J. Buhr, and K. D. Ingram, "Reduction of Salmonella in the crop of broiler chickens subjected to feed withdrawal," Poultry Science, vol. 79, no. 11, pp. 1566-1570, 2000.

[40] V. G. Stanley, D. M. Hutchinson, A. H. Reine, D. Corrier, and A. A. Hinton Jr., "Magnesium sulfate effects on coliform bacteria reduction in the intestines, ceca, and carcasses of broiler chickens," Poultry Science, vol. 71, no. 1, pp. 76-80, 1992.

[41] M. E. Berrang and J. S. Bailey, "On-line brush and spray washers to lower numbers of Campylobacter and Escherichia coli and presence of Salmonella on broiler carcasses during processing," Journal of Applied Poultry Research, vol. 18, no. 1, pp. 74-78, 2009.

[42] E. Pacholewicz, L. J. A. Lipman, A. Swart, A. H. Havelaar, and W. J. C. Heemskerk, "Pre-scald brushing for removal of solids and associated broiler carcass bacterial contamination," Poultry Science, vol. 95, no. 12, pp. 2979-2985, 2016.

[43] T. J. Humphrey, D. G. Lanning, and D. Beresford, "The effect of $\mathrm{pH}$ adjustment on the microbiology of chicken scald-tank 
water with particular reference to the death rate of salmonellas," Journal of Applied Bacteriology, vol. 51, no. 3, pp. 517-527, 1981.

[44] T. J. Humphrey and D. G. Lanning, "Salmonella and campylobacter contamination of broiler chicken carcasses and scald tank water: the influence of water $\mathrm{pH}$,' Journal of Applied Bacteriology, vol. 63, no. 1, pp. 21-25, 1987.

[45] A. J. Okrend, R. W. Johnston, and A. B. Moran, "Effect of acetic acid on the death rates at $52 \circ \mathrm{C}$ of salmonella newport, salmonella typhimurium and campylobacter jejuni in poultry scald water," Journal of Food Protection, vol. 49, no. 7, pp. 500503, 1986.

[46] M. E. Berrang, W. R. Windham, and R. J. Meinersmann, "Campylobacter, Salmonella, and Escherichia coli on broiler carcasses subjected to a high $\mathrm{pH}$ scald and low $\mathrm{pH}$ postpick chlorine dip," Poultry Science, vol. 90, no. 4, pp. 896-900, 2011.

[47] J. K. Northcutt, W. D. McNeal, K. D. Ingram, R. J. Buhr, and D. L. Fletcher, "Microbial recovery from genetically featherless broiler carcasses after forced cloacal fecal expulsion," Poultry Science, vol. 87, no. 11, pp. 2377-2381, 2008.

[48] M. T. Musgrove, J. A. Cason, D. L. Fletcher, N. J. Stern, N. A. Cox, and J. S. Bailey, "Effect of cloacal plugging on microbial recovery from partially processed broilers," Poultry Science, vol. 76, no. 3, pp. 530-533, 1997.

[49] R. J. Buhr, M. E. Berrang, and J. A. Cason, "Bacterial recovery from breast skin of genetically feathered and featherless broiler carcasses immediately following scalding and picking," Poultry Science, vol. 82, no. 10, pp. 1641-1647, 2003.

[50] T. Seliwiorstow, J. Baré, I. Van Damme, I. G. Algaba, M. Uyttendaele, and L. De Zutter, "Transfer of Campylobacter from a positive batch to broiler carcasses of a subsequently slaughtered negative batch: A quantitative approach," Journal of Food Protection, vol. 79, no. 6, pp. 896-901, 2016.

[51] C. J. Thomas and T. A. McMeekin, "Contamination of broiler carcass skin during commercial processing procedures: An electron microscopic study," Applied and Environmental Microbiology, vol. 40, no. 1, pp. 133-144, 1980.

[52] J. A. Dickens, R. J. Buhr, and J. A. Cason, "Subcutaneous temperature profile, skin appearance, and picking efficiency of immersion and spray scalded broiler carcasses," Poultry Science, vol. 78, no. 4, pp. 595-599, 1999.

[53] R. J. Buhr, J. M. Walker, D. V. Bourassa, A. B. Caudill, B. H. Kiepper, and H. Zhuang, "Impact of broiler processing scalding and chilling profiles on carcass and breast meat yield," Poultry Science, vol. 93, no. 6, pp. 1534-1541, 2014.

[54] N. A. Mir, A. Rafiq, F. Kumar, V. Singh, and V. Shukla, "Determinants of broiler chicken meat quality and factors affecting them: a review," Journal of Food Science and Technology, vol. 54, no. 10, pp. 2997-3009, 2017.

[55] S. Notermans and E. H. Kampelmacher, "Heat destruction of some bacterial strains attached to broiler skin," British Poultry Science, vol. 16, no. 4, pp. 351-361, 2007.

[56] R. W. A. W. Mulder, L. W. J. Dorresteijn, and J. V. Van Der Broek, "Cross-contamination during the scalding and plucking of broilers," British Poultry Science, vol. 19, no. 1, pp. 61-70, 1978.

[57] W. O. James, J. C. Prucha, R. L. Brewer et al., "Effects of countercurrent scalding and postscald spray on the bacteriologic profile of raw chicken carcasses," Journal of the American Veterinary Medical Association, vol. 201, no. 5, pp. 705-708, 1992.

[58] J. A. Cason, A. D. Whittemore, and A. D. Shackelford, "Aerobic bacteria and solids in a three-tank, two-pass, counterflow scalder," Poultry Science, vol. 78, no. 1, pp. 144-147, 1999.
[59] M. E. Berrang, R. J. Meinersmann, R. J. Buhr, N. A. Reimer, R. W. Philips, and M. A. Harrison, "Presence of Campylobacter in the respiratory tract of broiler carcasses before and after commercial scalding," Poultry Science, vol. 82, no. 12, pp. 19951999, 2003.

[60] R. J. Buhr, D. V. Bourassa, J. K. Northcutt, A. Hinton Jr., K. D. Ingram, and J. A. Cason, "Bacteria recovery from genetically feathered and featherless broiler carcasses after immersion chilling," Poultry Science, vol. 84, no. 9, pp. 1499-1504, 2005.

[61] J. A. Cason, A. Hinton Jr., and K. D. Ingram, "Coliform, Escherichia coli, and Salmonellae concentrations in a multipletank, counterflow poultry scalder," Journal of Food Protection, vol. 63, no. 9, pp. 1184-1188, 2000.

[62] J. A. Cason, R. J. Buhr, and A. Hinton Jr., "Unheated water in the first tank of a three-tank broiler scalder," Poultry Science, vol. 80, no. 11, pp. 1643-1646, 2001.

[63] S. M. Russell, "The effect of an acidic, copper sulfate-based commercial sanitizer on indicator, pathogenic, and spoilage bacteria associated with broiler chicken carcasses when applied at various intervention points during poultry processing," Poultry Science, vol. 87, no. 7, pp. 1435-1440, 2008.

[64] V. Lansini, D. S. V. Maia, D. da Fontoura Prates, A. S. de Lima, and W. P. da Silva, "Antibacterial activity of Timsen ${ }^{\circledR}$ (n-alkyl dimethyl benzyl ammonium chloride-40\%) in scalding and precooling water in poultry slaughterhouses," Journal of Food Science and Technology, vol. 54, no. 8, pp. 2607-2612, 2017.

[65] EFSA, "Panel on Biological Hazards (BIOHAZ): Scientific Opinion on Campylobacter in broiler meat production: control options and performance objectives and/or targets at different stages of the food chain," EFSA Journal, vol. 9, no. 4, 2011.

[66] V. F. Kaufman, A. A. Klose, H. G. Bayne, M. F. Pool, and H. Lineweaver, "Plant Processing of Sub-atmospheric Steam Scalded Poultry," Poultry Science, vol. 51, no. 4, pp. 1188-1194, 1972.

[67] T. E. Patrick, T. L. Goodwin, J. A. Collins, R. C. Wyche, and B. E. Love, "Steam versus hot-water scalding in reducing bacterial loads on the skin of commercially processed poultry.", Journal of Applied Microbiology, vol. 23, no. 4, pp. 796-798, 1972.

[68] M. Projahn, P. von Tippelskirch, T. Semmler, S. Guenther, T. Alter, and U. Roesler, "Contamination of chicken meat with extended-spectrum beta-lactamase producing- Klebsiella pneumoniae and Escherichia coli during scalding and defeathering of broiler carcasses," Food Microbiology, vol. 77, pp. 185191, 2019.

[69] V. M. Allen, M. H. Hinton, D. B. Tinker, C. Gibson, G. C. Mead, and C. M. Wathes, "Microbial cross-contamination by airborne dispersion and contagion during defeathering of poultry," British Poultry Science, vol. 44, no. 4, pp. 567-576, 2003.

[70] V. M. Allen, D. B. Tinker, M. H. Hinton, and C. M. Wathes, "Dispersal of micro-organisms in commercial defeathering systems," British Poultry Science, vol. 44, no. 1, pp. 53-59, 2003.

[71] J. W. Arnold, "Bacterial contamination on rubber picker fingers before, during, and after processing," Poultry Science, vol. 86, no. 12, pp. 2671-2675, 2007.

[72] J. A. Cason, A. Hinton Jr., and R. J. Buhr, "Impact of feathers and feather follicles on broiler carcass bacteria," Poultry Science, vol. 83, no. 8, pp. 1452-1455, 2004.

[73] M. E. Berrang, J. A. Dickens, and M. T. Musgrove, "Effects of hot water application after defeathering on the levels of Campylobacter, coliform bacteria, and Escherichia coli on broiler carcasses," Poultry Science, vol. 79, no. 11, pp. 1689-1693, 2000 . 
[74] J. D. Stopforth, R. O’Connor, M. Lopes, B. Kottapalli, W. E. Hill, and M. Samadpour, "Validation of individual and multiplesequential interventions for reduction of microbial populations during processing of poultry carcasses and parts," Journal of Food Protection, vol. 70, no. 6, pp. 1393-1401, 2007.

[75] J. A. Dickens and A. D. Whittemore, "Effects of acetic acid and hydrogen peroxide application during defeathering on the microbiological quality of broiler carcasses prior to evisceration," Poultry Science, vol. 76, no. 4, pp. 657-660, 1997.

[76] S. M. Russell and J. M. Walker, "The effect of evisceration on visible contamination and the microbiological profile of fresh broiler chicken carcasses using the nu-tech evisceration system or the conventional streamlined inspection system," Poultry Science, vol. 76, no. 5, pp. 780-784, 1997.

[77] E. Pacholewicz, S. A. Sura Barus, A. Swart, A. H. Havelaar, L. J. A. Lipman, and P. A. Luning, "Influence of food handlers' compliance with procedures of poultry carcasses contamination: A case study concerning evisceration in broiler slaughterhouses," Food Control, vol. 68, pp. 367-378, 2016.

[78] P. Singh, H. C. Lee, K. B. Chin, S. D. Ha, and I. Kang, "Quantification of loosely associated and tightly associated bacteria on broiler carcass skin using swabbing, stomaching, and grinding methods," Poultry Science, vol. 94, no. 12, pp. 30343039, 2015.

[79] M. E. Berrang, R. J. Buhr, J. A. Cason, and J. A. Dickens, "Microbiological consequences of skin removal prior to evisceration of broiler carcasses," Poultry Science, vol. 81, no. 1, pp. 134-138, 2002.

[80] R. W. Mulder and N. M. Bolder, "The effect of different bird washers on the microbiological quality of broiler carcasses," The Veterinary Quarterly, vol. 106, no. 14, pp. 124-130, 1981.

[81] O. A. Oyarzabal, C. Hawk, S. F. Bilgili, C. C. Warf, and G. K. Kemp, "Effects of postchill application of acidified sodium chlorite to control Campylobacter spp. and Escherichia coli on commercial broiler carcasses," Journal of Food Protection, vol. 67, no. 10, pp. 2288-2291, 2004.

[82] A. Giombelli and M. B. A. Gloria, "Prevalence of Salmonella and Campylobacter on broiler chickens from farm to slaughter and efficiency of methods to remove visible fecal contamination," Journal of Food Protection, vol. 77, no. 11, pp. 1851-1859, 2014.

[83] A. Giombelli, D. Hammerschmitt, M. F. Cerutti et al., "High pressure spray with water shows similar efficiency to trimming in controlling microorganisms on poultry carcasses," Poultry Science, vol. 94, no. 10, pp. 2589-2595, 2015.

[84] L. N. Bartenfeld, D. L. Fletcher, J. K. Northcutt, D. V. Bourassa, N. A. Cox, and R. J. Buhr, "The effect of high-level chlorine carcass drench on the recovery of Salmonella and enumeration of bacteria from broiler carcasses," Poultry Science, vol. 93, no. 11, pp. 2893-2899, 2014.

[85] P. Whyte, J. D. Collins, K. McGill, C. Monahan, and H. O'Mahony, "Quantitative investigation of the effects of chemical decontamination procedures on the microbiological status of broiler carcasses during processing," Journal of Food Protection, vol. 64, no. 2, pp. 179-183, 2001.

[86] J. Northcutt, D. Smith, K. D. Ingram, A. Hinton Jr., and M. Musgrove, "Recovery of bacteria from broiler carcasses after spray washing with acidified electrolyzed water or sodium hypochlorite solutions," Poultry Science, vol. 86, no. 10, pp. 2239-2244, 2007.

[87] H. Wang, J. Qi, D. Duan, Y. Dong, X. Xu, and G. Zhou, “Combination of a novel designed spray cabinet and electrolyzed water to reduce microorganisms on chicken carcasses," Food Control, vol. 86, pp. 200-206, 2018.

[88] G. Kere Kemp, M. L. Aldrich, M. L. Guerra, and K. R. Schneider, "Continuous online processing of fecal- and ingesta contaminated poultry carcasses using an acidified sodium chlorite antimicrobial intervention," Journal of Food Protection, vol. 64, no. 6, pp. 807-812, 2001.

[89] G. K. Kemp, M. L. Aldrich, and A. L. Waldroup, "Acidified sodium chlorite antimicrobial treatment of broiler carcasses," Journal of Food Protection, vol. 63, no. 8, pp. 1087-1092, 2000.

[90] A. Hinton Jr. and K. D. Ingram, "Microbicidal activity of tripotassium phosphate and fatty acids toward spoilage and pathogenic bacteria associated with poultry," Journal of Food Protection, vol. 68, no. 7, pp. 1462-1466, 2005.

[91] A. Hinton Jr., J. K. Northcutt, J. A. Cason, D. P. Smith, and K. D. Ingram, "Bacterial populations of broiler carcasses washed in mixtures of potassium hydroxide and lauric acid," Journal of Applied Poultry Research, vol. 16, no. 3, pp. 387-391, 2007.

[92] A. Hinton Jr. and K. D. Ingram, "Use of oleic acid to reduce the population of the bacterial flora of poultry skin," Journal of Food Protection, vol. 63, no. 9, pp. 1282-1286, 2000.

[93] S. M. Jiménez, P. Destefanis, M. S. Salsi, M. C. Tiburzi, and M. E. Pirovani, "Predictive model for reduction of Escherichia coli during acetic acid decontamination of chicken skin," Journal of Applied Microbiology, vol. 99, no. 4, pp. 829-835, 2005.

[94] D. Shin, G. Kakani, V. A. Molina, J. M. Regenstein, H. S. Choe, and M. X. Sánchez-Plata, "Effect of kosher salt application on microbial profiles of poultry carcasses," Poultry Science, vol. 91, no. 12, pp. 3247-3252, 2012.

[95] L. L. Duffy, P. J. Blackall, R. N. Cobbold, and N. Fegan, "Quantitative effects of in-line operations on Campylobacter and Escherichia coli through two Australian broiler processing plants," International Journal of Food Microbiology, vol. 188, pp. 128-134, 2014.

[96] E. Pacholewicz, A. Swart, M. Schipper et al., "A comparison of fluctuations of Campylobacter and Escherichia coli concentrations on broiler chicken carcasses during processing in two slaughterhouses," International Journal of Food Microbiology, vol. 205, pp. 119-127, 2015.

[97] Y. Agerso, F. M. Aarestrup, K. Pedersen, A. M. Seyfarth, T. Struve, and H. Hasman, "Prevalence of extended-spectrum cephalosporinase (ESC)-producing Escherichia coli in Danish slaughter pigs and retail meat identified by selective enrichment and association with cephalosporin usage," Journal of Antimicrobial Chemotherapy, vol. 67, no. 3, Article ID dkr507, pp. 582588, 2012.

[98] C. Belmar Campos, I. Fenner, N. Wiese et al., "Prevalence and genotypes of extended spectrum beta-lactamases in Enterobacteriaceae isolated from human stool and chicken meat in Hamburg, Germany," International Journal of Medical Microbiology, vol. 304, no. 5-6, pp. 678-684, 2014.

[99] A. Kola, C. Kohler, Y. Pfeifer et al., "High prevalence of extended-spectrum- $\beta$-lactamase-producing Enterobacteriaceae in organic and conventional retail chicken meat, Germany," Journal of Antimicrobial Chemotherapy, vol. 67, no. 11, Article ID dks295, pp. 2631-2634, 2012.

[100] V. M. Allen, C. H. Burton, J. E. L. Corry, G. C. Mead, and D. E. Tinker, "Investigation of hygiene aspects during air chilling of poultry carcases using a model rig," British Poultry Science, vol. 41, no. 5, pp. 575-583, 2000.

[101] V. M. Allen, J. E. L. Corry, C. H. Burton, R. T. Whyte, and G. C. Mead, "Hygiene aspects of modern poultry chilling," 
International Journal of Food Microbiology, vol. 58, no. 1-2, pp. 39-48, 2000.

[102] S. Barbut, L. F. Moza, F. Nattress, B. Dilts, and C. O. Gill, “The microbiological conditions of air- or water-chilled carcasses produced at the same poultry packing plant," Journal of Applied Poultry Research, vol. 18, no. 3, pp. 501-507, 2009.

[103] M. E. Berrang, R. J. Meinersmann, D. P. Smith, and H. Zhuang, "The effect of chilling in cold air or ice water on the microbiological quality of broiler carcasses and the population of Campylobacter," Poultry Science, vol. 87, no. 5, pp. 992-998, 2008.

[104] M. X. Sánchez, W. M. Fluckey, M. M. Brashears, and S. R. McKee, "Microbial profile and antibiotic susceptibility of Campylobacter spp. and Salmonella spp. in broilers processed in air-chilled and immersion-chilled environments," Journal of Food Protection, vol. 65, no. 6, pp. 948-956, 2002.

[105] L. Zhang, J. Y. Jeong, K. K. Janardhanan, E. T. Ryser, and I. Kang, "Microbiological quality of water immersion - Chilled and airchilled broilers," Journal of Food Protection, vol. 74, no. 9, pp. 1531-1535, 2011.

[106] C. James, S. J. James, N. Hannay et al., "Decontamination of poultry carcasses using steam or hot water in combination with rapid cooling, chilling or freezing of carcass surfaces," International Journal of Food Microbiology, vol. 114, no. 2, pp. 195-203, 2007.

[107] A. Patsias, A. V. Badeka, I. N. Savvaidis, and M. G. Kontominas, "Combined effect of freeze chilling and MAP on quality parameters of raw chicken fillets," Food Microbiology, vol. 25, no. 4, pp. 575-581, 2008.

[108] B. D. Chaves, I. Y. Han, P. L. Dawson, and K. Northcutt, "Survival of artificially inoculated Escherichia coli and Salmonella Typhimurium on the surface of raw poultry products subjected to crust freezing," Poultry Science, vol. 90, no. 12, pp. 2874-2878, 2011.

[109] J. A. Dickens, M. E. Berrang, and N. A. Cox, "Efficacy of an herbal extract on the microbiological quality of broiler carcasses during a simulated chill," Poultry Science, vol. 79, no. 8, pp. 12001203, 2000.

[110] L. C. T. Souza Jr., J. G. Pereira, T. L. B. Spina, T. B. Izidoro, A. C. Oliveira, and J. P. A. N. Pinto, "Microbiological evaluation of chicken carcasses in an immersion chilling system with water renewal at 8 and 16 hours," Journal of Food Protection, vol. 75, no. 5, pp. 973-975, 2012.

[111] J. A. Cason, M. E. Berrang, R. J. Buhr, and N. A. Cox, "Effect of prechill fecal contamination on numbers of bacteria recovered from broiler chicken carcasses before and after immersion chilling," Journal of Food Protection, vol. 67, no. 9, pp. 1829-1833, 2004.

[112] M. Kameyama, T. Chuma, T. Nishimoto et al., "Effect of cooled and chlorinated chiller water on campylobacter and coliform counts on broiler carcasses during chilling at a middle-size poultry processing plant," Journal of Veterinary Medical Science, vol. 74, no. 1, pp. 129-133, 2012.

[113] S. M. Russell and S. P. Axtell, "Monochloramine versus sodium hypochlorite as antimicrobial agents for reducing populations of bacteria on broiler chicken carcasses," Journal of Food Protection, vol. 68, no. 4, pp. 758-763, 2005.

[114] J. H. Chen, Y. Ren, J. Seow, T. Liu, W. S. Bang, and H. G. Yuk, "Intervention technologies for ensuring microbiological safety of meat: current and future trends," Comprehensive Reviews in Food Science and Food Safety, vol. 11, no. 2, pp. 119-132, 2012.
[115] A. Al-Nehlawi, J. Saldo, L. F. Vega, and S. Guri, "Effect of high carbon dioxide atmosphere packaging and soluble gas stabilization pre-treatment on the shelf-life and quality of chicken drumsticks," Meat Science, vol. 94, no. 1, pp. 1-8, 2013.

[116] J. A. Byrd, A. R. Sams, B. M. Hargis, and D. J. Caldwell, "Effect of selected modified atmosphere packaging on Campylobacter survival in raw poultry," Poultry Science, vol. 90, no. 6, pp. 1324$1328,2011$.

[117] H. Meredith, V. Valdramidis, B. T. Rotabakk, M. Sivertsvik, D. McDowell, and D. J. Bolton, "Effect of different modified atmospheric packaging (MAP) gaseous combinations on Campylobacter and the shelf-life of chilled poultry fillets," Food Microbiology, vol. 44, pp. 196-203, 2014.

[118] A. Rouger, O. Tresse, and M. Zagorec, "Bacterial contaminants of poultry meat: sources, species, and dynamics," Microorganisms, vol. 5, no. 3, p. 50, 2017.

[119] K. W. McMillin, "Advancements in meat packaging," Meat Science, vol. 132, pp. 153-162, 2017.

[120] S. Ravishankar, L. Zhu, C. W. Olsen, T. H. McHugh, and M. Friedman, "Edible apple film wraps containing plant antimicrobials inactivate foodborne pathogens on meat and poultry products," Journal of Food Science, vol. 74, no. 8, pp. M440M445, 2009.

[121] K. H. Seol, D. G. Lim, A. Jang, C. Jo, and M. Lee, "Antimicrobial effect of $\kappa$-carrageenan-based edible film containing ovotransferrin in fresh chicken breast stored at $5^{\circ} \mathrm{C}$, Meat Science, vol. 83, no. 3, pp. 479-483, 2009.

[122] M. Gulmez, N. Oral, and L. Vatansever, "The effect of water extract of sumac (Rhus coriaria L.) and lactic acid on decontamination and shelf life of raw broiler wings," Poultry Science, vol. 85, no. 8, pp. 1466-1471, 2006.

[123] P. N. Haughton, J. G. Lyng, D. J. Morgan, D. A. Cronin, S. Fanning, and P. Whyte, "Efficacy of high-intensity pulsed light for the microbiological decontamination of chicken, associated packaging, and contact surfaces," Foodborne Pathogens and Disease, vol. 8, no. 1, pp. 109-117, 2011.

[124] A. Kašková, O. Ondrašovičová, M. Vargová, M. Ondrašovič, and J. Venglovský, "Application of peracetic acid and quarternary ammonium disinfectants as a part of sanitary treatment in a poultry house and poultry processing plant," Zoonoses and Public Health, vol. 54, no. 3-4, pp. 125-130, 2007.

[125] E. M. M. Rossoni and C. C. Gaylarde, "Comparison of sodium hypochlorite and peracetic acid as sanitising agents for stainless steel food processing surfaces using epifluorescence microscopy," International Journal of Food Microbiology, vol. 61, no. 1, pp. 81-85, 2000.

[126] V. M. Allen, C. H. Burton, D. J. Wilkinson et al., "Evaluation of the performance of different cleaning treatments in reducing microbial contamination of poultry transport crates," British Poultry Science, vol. 49, no. 3, pp. 233-240, 2008.

[127] V. M. Allen, R. T. Whyte, C. H. Burton et al., "Effect of ultrasonic treatment during cleaning on the microbiological condition of poultry transport crates," British Poultry Science, vol. 49, no. 4, pp. 423-428, 2008.

[128] V. M. Soares, J. G. Pereira, C. M. Zanette et al., "Cleaning conveyor belts in the chicken-cutting area of a poultry processing plant with $45^{\circ} \mathrm{C}$ water," Journal of Food Protection, vol. 77, no. 3, pp. 496-498, 2014.

[129] N. J. Rowan, S. Espie, J. Harrower, J. G. Anderson, L. Marsili, and S. J. MacGregor, "Pulsed-plasma gas-discharge inactivation of microbial pathogens in chilled poultry wash water," Journal of Food Protection, vol. 70, no. 12, pp. 2805-2810, 2007. 
[130] T. Kim, J. L. Silva, and T. C. Chen, "Effects of UV irradiation on selected pathogens in peptone water and on stainless steel and chicken meat," Journal of Food Protection, vol. 65, no. 7, pp. 1142-1145, 2002.

[131] C. Sommers, N. W. Gunther, and S. Sheen, "Inactivation of Salmonella spp., pathogenic Escherichia coli, Staphylococcus spp., or Listeria monocytogenes in chicken purge or skin using a 405-nm LED array," Food Microbiology, vol. 64, pp. 135-138, 2017.

[132] P. F. M. Teunis, E. G. Evers, P. D. Hengeveld, C. M. Dierikx, C. C. C. H. Wielders, and E. Van Duijkeren, "Time to acquire and lose carriership of ESBL/ pAmpC producing E. coli in humans in the Netherlands," PLoS ONE, vol. 13, no. 3, 2018.

[133] M. Caltagirone, E. Nucleo, M. Spalla et al., "Occurrence of extended spectrum $\beta$-lactamases, KPC-Type, and MCR-1.2producing enterobacteriaceae from wells, river water, and wastewater treatment plants in Oltrepò Pavese area, Northern Italy," Frontiers in Microbiology, vol. 8, 2017.

[134] A. A. Diallo, H. Brugère, M. Kérourédan et al., "Persistence and prevalence of pathogenic and extended-spectrum betalactamase-producing Escherichia coli in municipal wastewater treatment plant receiving slaughterhouse wastewater," Water Research, vol. 47, no. 13, pp. 4719-4729, 2013.

[135] V. Dupouy, B. Doublet, N. Arpaillange et al., "Dominant plasmids carrying extended-spectrum $\beta$-lactamases blaCTX$\mathrm{M}$ genes in genetically diverse Escherichia coli from slaughterhouse and urban wastewaters," Environmental Microbiology Reports, 2016.

[136] L. Gao, J. Hu, X. Zhang et al., "Dissemination of ESBLproducing Escherichia coli of chicken origin to the nearby river water," Journal of Molecular Microbiology and Biotechnology, vol. 24, no. 4, pp. 279-285, 2014.

[137] S. Notermans and E. H. Kampelmacher, "Further studies on the attachment of bacteria to skin," British Poultry Science, vol. 16, no. 5, pp. 487-496, 1975. 


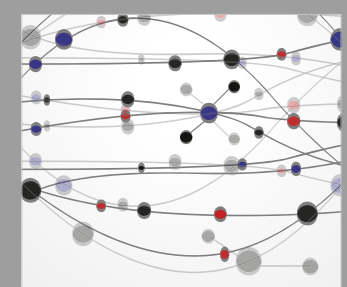

The Scientific World Journal
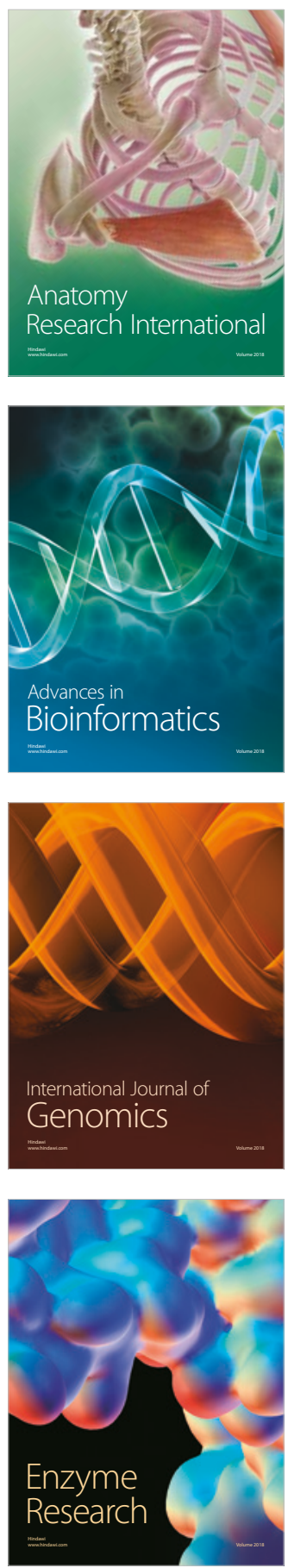
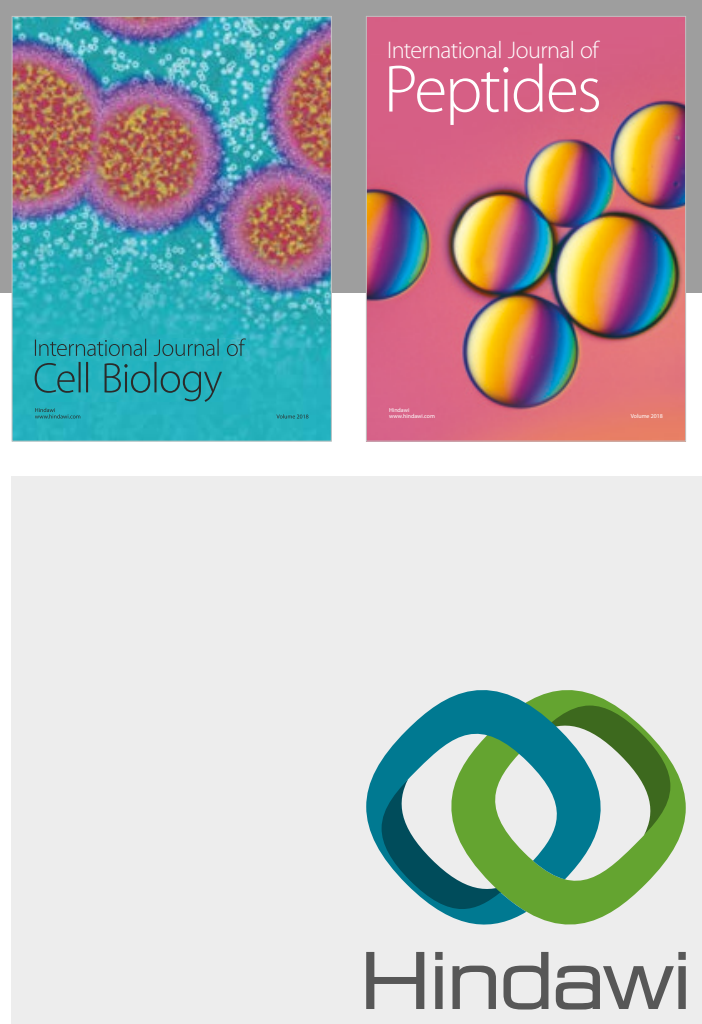

Submit your manuscripts at

www.hindawi.com
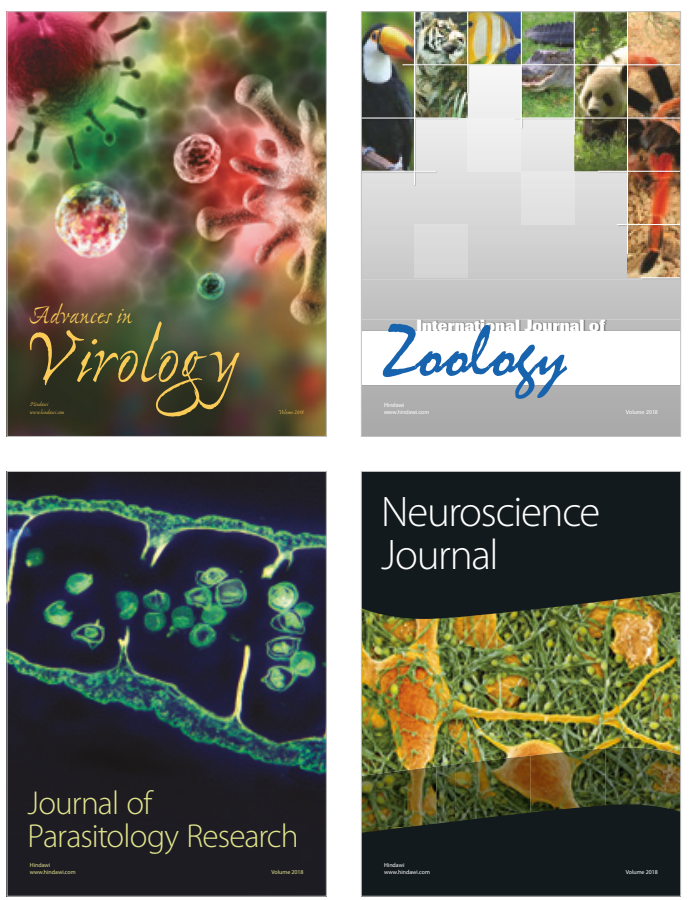
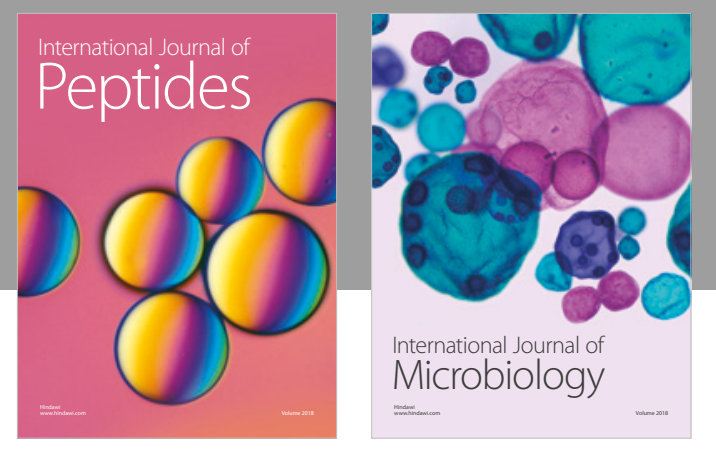

nternational Journal of Microbiology
Journal of
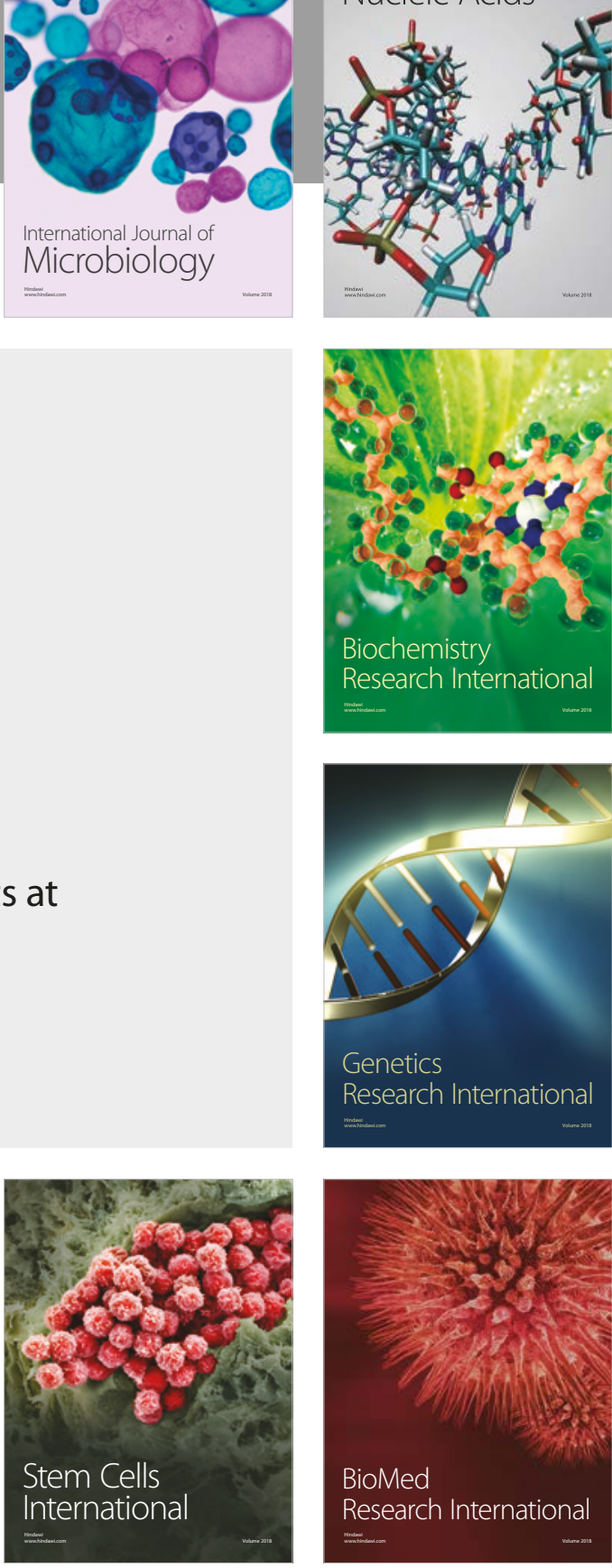
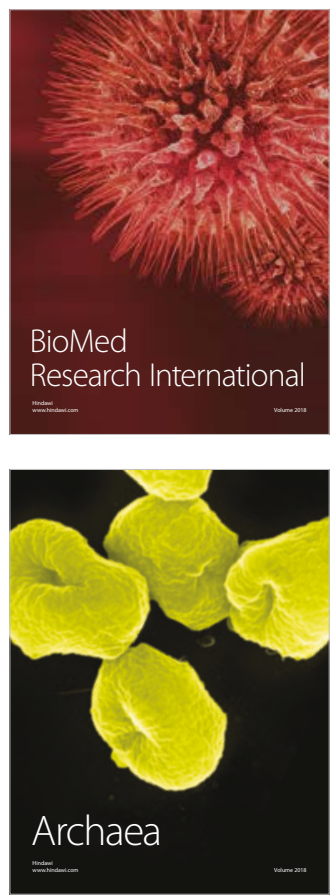